\title{
Effect of Cured Time on Creep of Lightweight Aggregate Concrete
}

\author{
Haibin Yang, Xiaoxiao Xu, Hongzhi Cui, and Zitao Lin \\ Guangdong Provincial Key Laboratory of Durability for Marine Engineering, College of Civil Engineering, \\ Shenzhen University, Shenzhen 518060, China \\ Tommy Yiu Lo \\ Department of Engineering and Architecture, City University of Hong Kong
}

\begin{abstract}
Creep and shrinkage are such properties that will occur in concrete when they are under load and exposed to surrounding. Since this property will cause deformation which may decrease the design strength of the concrete, it is necessary to do have more knowledge on this phenomenon. So, we will study the effect of creep on 7 and 14 days of cured time of specimens which sealed or unsealed will be considered, respectively. The specimens have shown how the concrete strains when they are under sustained load with time. Besides, the sealed specimens have shown how the basic creep is different from the total creep of concrete. Further, the specimens of loading at different ages have shown how the age at application of load influences creep. The result of the experiment has shown the relationship of strain under sustained load and time. Moreover, it is shown that creep is mainly related to the strength developed in the concrete.
\end{abstract}

Keywords: sustained load, creep, shrinkage, cured time

\section{INTRODUCTION}

Lightweight aggregate concrete (LWAC) has been widespread used in nowadays construction industry. Not only has it a relative high strength and a wide range of workability that can be subject to heavy loading and made for different shapes, respectively, but also it has obvious advantages of LWAC in its light weight, good thermal properties, fire resistance, and seismic resistance as well as environmental friendliness (Wilson \& Malhotra, 1988). It has been widely applied in the construction of high-rise buildings, long-span bridges, and marine structures in harsh environments (Waldron et al., 2005). However, as we know that concrete is not efficacious forever, the strength of the concrete may reduce with time because of some of its behaviors. It is very important to gain more knowledge and pay more attention to this problem as it will greatly affect the serviceability and safety of structures.

When concrete is under loading, it responds both immediately and in a time-dependent manner. The deformation of concrete gradually increases with time and will be much larger than its instantaneous values. Creep is such a phenomenon that causes the deformation of concrete to increase with time under sustained stress (Yue, 1992). It is an important part of total deformation of concrete as it is generally larger than the elastic deformation, and such inelastic and time-dependent strains cause increase in deformation and curvature, losses of prestress, and redistribution of stress and internal actions (Gilbert, 1988). Creep can be divided into basic creep and drying creep. Basic creep occurs under conditions of no moisture movement to or from the environment, while drying creep is the additional creep caused by drying (American Concrete Institute, 1982). Furthermore, it was well known that creep can be influenced by many factors, such as humidity, temperature, effects of admixtures, the properties of aggregates, the stress/ strength ratio, water/cement ratio, the size of concrete, properties of cement, etc. (Gvozdev, 1966; Hummel, 1959; Kordina, 1960; L'Hermite, 1959; Meyers \& Slate, 1970; Nasser \& Neville, 1967; Neville \& Brook, 1983; Neville \& Brooks, 1987; Neville, Staunton, \& Bonn, 1966; Raina, 1989; Troxell, Raphael, \& Davis, 1958; Wanger, 1958). Besides, shrinkage is another behavior of concrete, which reduces the strength. It is very similar to creep, but its strain is independent of stress. It is caused by the chemical reaction or loss of water during the drying process, resulting in the reduction in volume of the concrete (Daye \& Fu, 1992). Such situation causes unsightly cracking, which leads to the serviceability and durability of structures.

Until nowadays, majority of structures have not been considered influencing these two behaviors among their design lifetime. Although few structures may be taken into account, they are inadequate. 
As Gilbert (1988) stated that in order to accurately and efficiently predict the effects of these two behaviors, it is necessary to have some reliable data for the creep and shrinkage of a particular concrete mix. It is necessary to have a better understanding on these two behaviors in order to continue the developments in the application of concrete in construction industry.

In spite of some research has reported about creep and shrinkage, LWAC has yet complete. So, the research aims to determine the creep and shrinkage behavior of LWAC (6-mm size aggregate) of different aging under a constant temperature, and humidity is a very prospective project. The creep and shrinkage behavior of 7- and 17-day LWAC - unsealed/ sealed by PVC plastic, which will compare with the theoretical findings to find out whether there is any difference between them. Besides, the sealed and unsealed concrete of the same age will compare with each other to determine the effect of water lose on the creep behavior. Further, the creep and shrinkage behavior of the 7-day sealed and unsealed LWAC will compare with 14-day sealed and unsealed concrete, respectively, in order to find out the effect of aging on the creep behavior of concrete. Based on the above results, more knowledge of creep behavior of a particular mix will be gained.

\section{EXPERIMENT METHODOLOGY AND MATERIALS PREPARED}

The experimental investigations were focused on the determination of the creep and shrinkage behavior under constant temperature and humidity. Experiment stated in British Stand (BS) 812: part 2, 1995 are followed to find out the properties of the 6-mm lightweight aggregates, such as the bulk density, the size distribution, and the water absorption, in order to design mix for the experiment. Based on the BS 812: Part 2, 1995, the properties of the aggregates were found, and the bulk density is about $625.03 \mathrm{~kg} / \mathrm{m}^{3}$. According to the result obtained from the test of water absorption and bulk density of aggregates, the data were analyzed by computer, and the design mix of concrete was generated which is shown in Table 1.

Table 1. The proportion of concrete mix.

\begin{tabular}{ll}
\hline Cement & $45.0 \mathrm{~kg}$ \\
Coarse leca $(6 \mathrm{~mm})$ & $51.4 \mathrm{~kg}$ \\
Fine sand & $74.3 \mathrm{~kg}$ \\
Water & $25.3 \mathrm{~kg}$ \\
WRDA88 & $225 \mathrm{cc}$ \\
Superplasticizer & $110 \mathrm{cc}$ \\
\hline
\end{tabular}

After weight of all materials which was we need in mix, half amount of water weighted was poured into the aggregate and mixed evenly to pre-wet the aggregate. Meanwhile, the WRDA88 also poured into remaining water. Then superplasticizer was added to the mix of the aggregate, cement, fine sand, and water in a $0.1-\mathrm{m}^{3}$ concrete mixer. The mixer was stopped until the concrete was mixed thoroughly. In this proceeding, we also measure slump test that is helpful in characterizing LWAC. When mixing was over, the LWAC was poured into steel molds and compacted on a vibration table with BS 1881: Part 108: 1983. After casting, all the specimens were covered with a plastic sheet to prevent water loss and demolded after $24 \mathrm{~h}$. The LWAC were cured in a fog room until the test age.

In this experiment, twelve $\Phi 150 \mathrm{~mm} \times 300 \mathrm{~mm}$ cylinders and eight $150 \mathrm{~mm} \times 150 \mathrm{~mm} \times 150 \mathrm{~mm}$ cubes specimens are used for experiment. The 12 cylindrical concrete and 8 cube concrete were places inside the room with constant temperature and humidity, and allowed to cure for 7 and 14 days, the temperature and humidity have been shown in Figures 1 and 2 .

The Standard Test Method for creep of concrete in compression stated in ASTM C 512:87 ${ }^{1}$ are then followed to find out the creep behavior of the concrete. Sealed and unsealed specimens are used in the test to determine different types of creep.

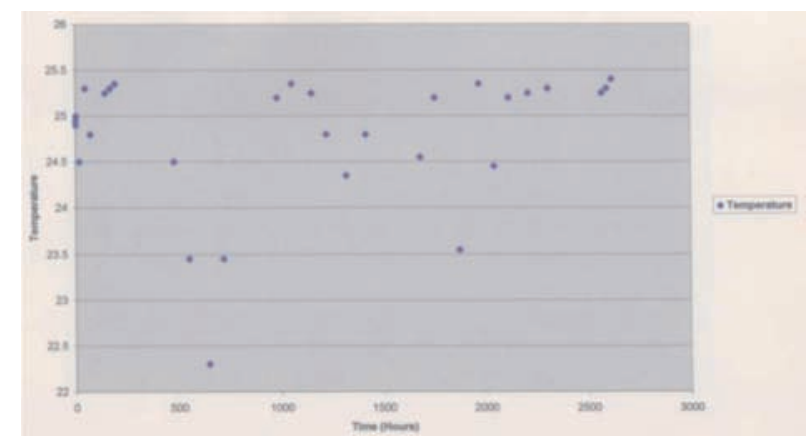

Figure 1. Temperature of the room.

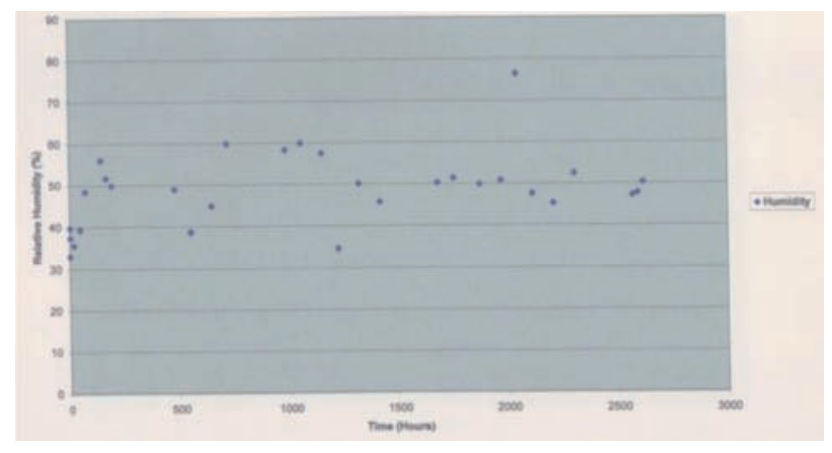

Figure 2. Relative humidity of the room. 


\section{EXPERIMENTAL PROCESS}

As a result of only the plastic sheet covering on the surface of top, the surface is not smooth in order to test the accuracy of each specimen must be smooth that four of the concrete was ground. PVC plastic coat was used to coat the surface of two smoothed cylindrical concrete (for creep test) and totally coated one unsmooth concrete (for shrinkage text). Sealant was injected on the joins of the specimens to prevent the loss of water. Two perpendicular lines passing through the center of the top of the cylindrical concrete were drawn. Then, four and two vertical lines equally divided the surface of the concrete were drawn for the four smoothed (for creep test) and two unsmooth concrete (for shrinkage test), respectively. The marks were roughed by sand paper and steel points were stuck on it by glue with the aids of the steel calibrator to ensure the distance between points. Two concrete cubes were used to do the compression test to find out the compression strength of the concrete on the data of loading.

Table 2 was shown that the six cylinders concrete (with the same age) was marked with number and direction (W, S, W, and N).

Table 2. Marked direction of six cylinders concrete.

\begin{tabular}{|c|c|c|c|c|c|}
\hline \multicolumn{3}{|c|}{7 days cured } & \multicolumn{3}{|c|}{14 days cured } \\
\hline $\begin{array}{c}\text { Cylinder } \\
\text { no. }\end{array}$ & $\begin{array}{c}\text { Sealed/ } \\
\text { unsealed }\end{array}$ & $\begin{array}{c}\text { Direction } \\
\text { marked }\end{array}$ & $\begin{array}{c}\text { Cylinder } \\
\text { no. }\end{array}$ & $\begin{array}{l}\text { Sealed/ } \\
\text { unsealed }\end{array}$ & $\begin{array}{c}\text { Direction } \\
\text { marked }\end{array}$ \\
\hline 1 & Sealed & $\mathrm{S}$ and $\mathrm{N}$ & 7 & Sealed & $\mathrm{S}$ and $\mathrm{N}$ \\
\hline 2 & Unsealed & $\mathrm{S}$ and $\mathrm{N}$ & 8 & Unsealed & $\mathrm{S}$ and $\mathrm{N}$ \\
\hline 3 & Sealed & $\begin{array}{l}\mathrm{E}, \mathrm{S}, \mathrm{W} \text {, } \\
\text { and } \mathrm{N}\end{array}$ & 9 & Sealed & $\begin{array}{l}\mathrm{E}, \mathrm{S}, \mathrm{W} \text {, } \\
\text { and } \mathrm{N}\end{array}$ \\
\hline 4 & Sealed & $\begin{array}{l}\mathrm{E}, \mathrm{S}, \mathrm{W} \\
\text { and } \mathrm{N}\end{array}$ & 10 & Sealed & $\begin{array}{l}\mathrm{E}, \mathrm{S}, \mathrm{W} \\
\text { and } \mathrm{N}\end{array}$ \\
\hline 5 & Unsealed & $\begin{array}{l}\mathrm{E}, \mathrm{S}, \mathrm{W} \\
\text { and } \mathrm{N}\end{array}$ & 11 & Unsealed & $\begin{array}{l}\mathrm{E}, \mathrm{S}, \mathrm{W} \text {, } \\
\text { and } \mathrm{N}\end{array}$ \\
\hline 6 & Unsealed & $\begin{array}{l}\mathrm{E}, \mathrm{S}, \mathrm{W} \text {, } \\
\text { and } \mathrm{N}\end{array}$ & 12 & Unsealed & $\begin{array}{l}\mathrm{E}, \mathrm{S}, \mathrm{W} \\
\text { and } \mathrm{N}\end{array}$ \\
\hline
\end{tabular}

Before we are intend to loading, a cylindrical concrete was placed on the bottom plate of the spring-load creep frame. Cylinder No. 3/9 was placed on the cylinder concrete with cylinder No. 4, 5, 6/10, 11, and 12 on the top, as is shown in Figure 3. Another cylindrical concrete was placed on the top. Cylinder No. 1, 2/7, and 8 were set aside to act as control specimens.

The numbers and directions were checked to ensure that they were in good order. The lines drawn were checked to ensure that they were joined together. The top and the bottom cylinder were checked to ensure that they were fitted to the center part of the top and bottom plate without trends to any side. The nuts of frame were slightly locked by hands, and strains of different direction of cylinders were measured by the strain-measuring device. The pump head was pieced on the top of the top plate with apparatus with a metal ball on the top of it (Figure 4). The pump bottom was locked, and stress of about $30 \%$ of the strength of concrete was pumped up (4000 psi for 7 days and 4400 psi for 14 days). The nuts were slightly locked by hand, and the pump bottom was unlocked. Then, the pump head was removed. Strains were immediately measured after the load was applied, strains were measured continuously (daily for 1 week, weekly until the end of 1 month, and monthly later on) for about 3 months.

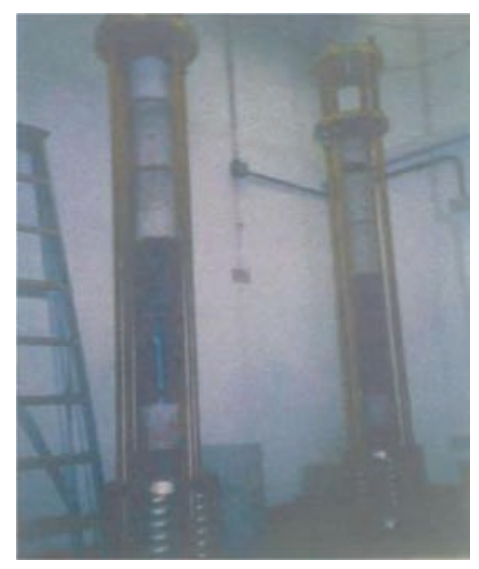

Figure 3. The spring-loaded creep frame.

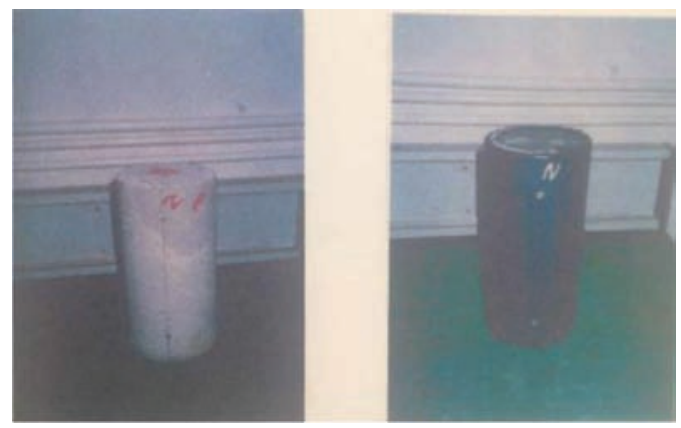

Figure 4. Unsealed and sealed specimen.

When we want to cancel the loading, we need to care about the following contents. The head of the pump was placed on the top of the top plate, and an apparatus with a metal ball was placed on the top of the pump head. The pump bottom was locked and pumped up to the value approximately smaller than the load applied, and the nuts were tried to be unlocked by hand. When the pump bottom was unlocked, the load can be removed. The nuts were slightly locked by hand again to prevent the cylinder from being collapsed. Then, the pump head was removed, and strains were measured immediately and continuously for few days, and the 
compression strength test of the unsealed specimens was done after recovery for 7 days.

\section{RESULT AND DISCUSSION}

\subsection{Result}

According to the design mix of concrete, the properties of LWAC are as follows in Tables 3-5.

Table 3. The physical properties of LWAC.

\begin{tabular}{lc}
\hline Slump $(\mathrm{mm})$ & 45 \\
Bulk density $\left(\mathrm{kg} / \mathrm{m}^{3}\right)$ & 1682.4 \\
\hline
\end{tabular}

Table 4. The compression strength of different age.

\begin{tabular}{|c|c|c|c|c|}
\hline $\begin{array}{l}\text { Age } \\
\text { (days) }\end{array}$ & $\begin{array}{l}\text { Load of } \\
150 \times \mathrm{mm} \\
150 \times \mathrm{mm} \\
150 \mathrm{~mm} \\
\text { cube } \\
(\mathrm{KN})\end{array}$ & $\begin{array}{c}\text { Compression } \\
\text { strength } \\
\text { of cube } \\
\left(\mathrm{N} / \mathrm{mm}^{2}\right)\end{array}$ & $\begin{array}{l}\text { Compression } \\
\text { strength of } \\
\text { cylindrical } \\
\text { concrete } \\
\left(\mathrm{N} / \mathrm{mm}^{2}\right)\end{array}$ & $\begin{array}{l}\text { Load } \\
\text { applied for } \\
\text { creep test } \\
\text { (psi) }\end{array}$ \\
\hline 7 & 647.5 & 28.33 & 22.66 & $\begin{array}{l}4000 \\
\text { (29.5\% of } \\
\text { compression } \\
\text { strength) }\end{array}$ \\
\hline 14 & 691.5 & 30.73 & 24.58 & $\begin{array}{l}4400 \\
\text { (30.2\% of } \\
\text { compression } \\
\text { strength) }\end{array}$ \\
\hline 28 & 701.5 & 31.18 & 24.94 & - \\
\hline
\end{tabular}

Table 5. The compression strength of unsealed specimens after recovery.

\begin{tabular}{lcc}
\hline Type of specimen & $\begin{array}{c}\text { Load of cylindrical } \\
\text { concrete }(\mathrm{KN})\end{array}$ & $\begin{array}{c}\text { Compression } \\
\text { strength }\left(\mathrm{KN} / \mathbf{m m}^{2}\right)\end{array}$ \\
\hline Shrinkage specimen & 489 & 27.67 \\
$\begin{array}{l}\text { 7-day creep } \\
\text { specimen }\end{array}$ & 492 & 27.84 \\
$\begin{array}{l}\text { 14-day creep } \\
\text { specimen }\end{array}$ & 512.5 & 29 \\
\hline
\end{tabular}

The result of value of shrinkage and creep has been shown in Figures 5-12.

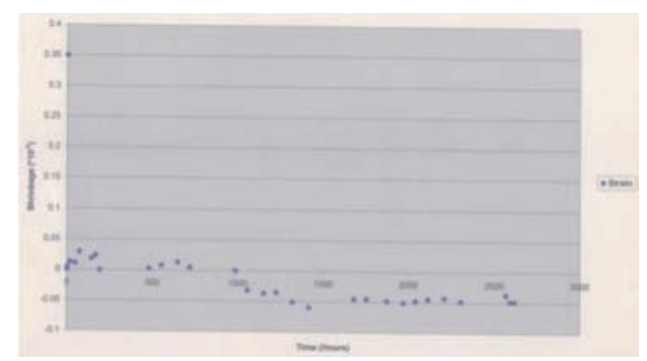

Figure 5. Shrinkage of 7-day sealed specimen.

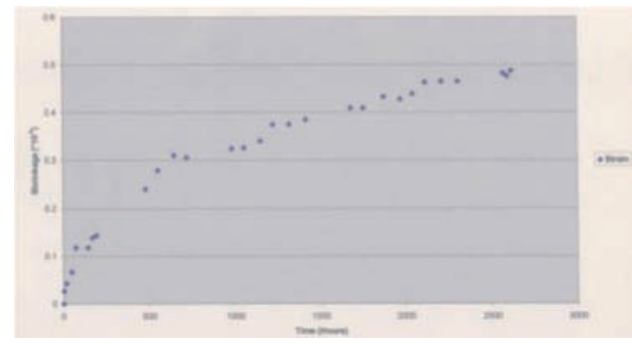

Figure 6. Shrinkage of 7-day unsealed specimen.

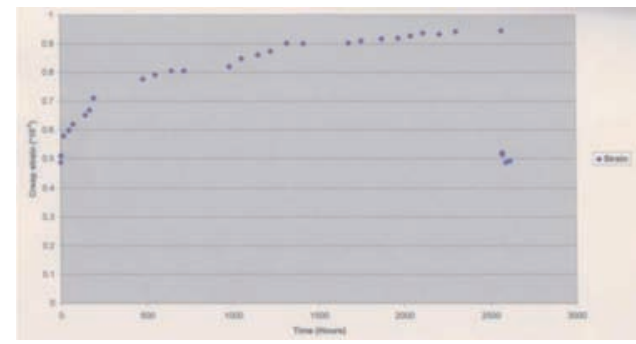

Figure 7. Creep of 7-day sealed specimen.

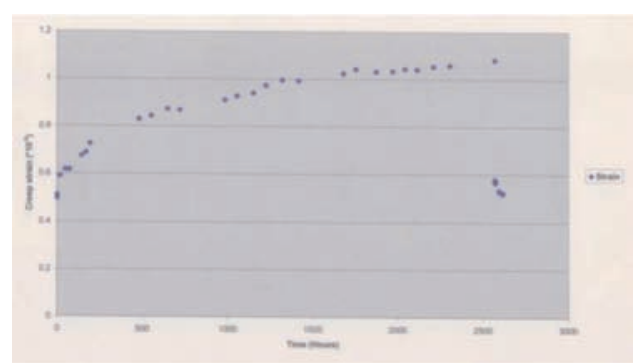

Figure 8. Creep of 7-day unsealed specimen.

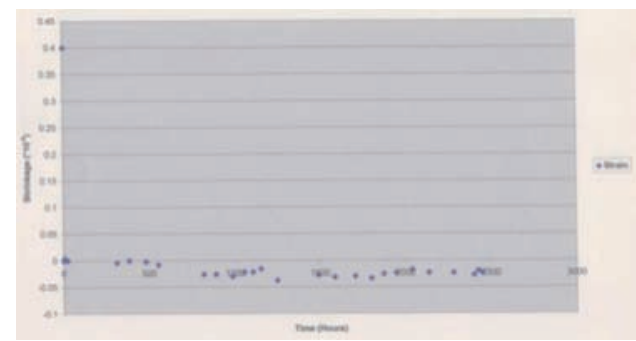

Figure 9. Shrinkage of 14-day sealed specimen.

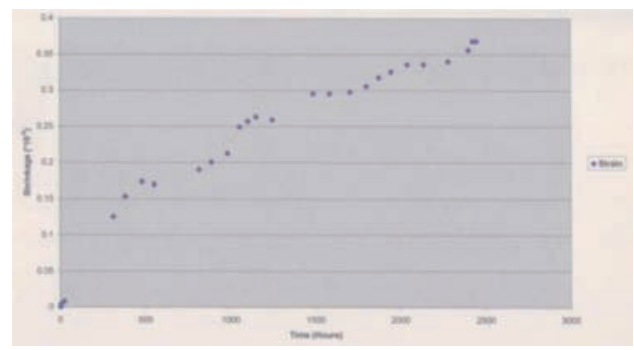

Figure 10. Shrinkage of 14-day unsealed specimen. 


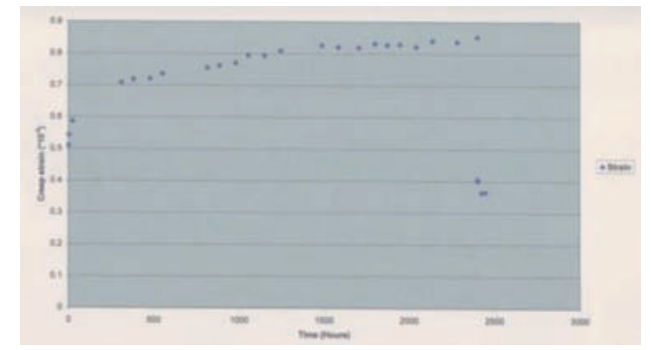

Figure 11. Creep of 14-day sealed specimen.

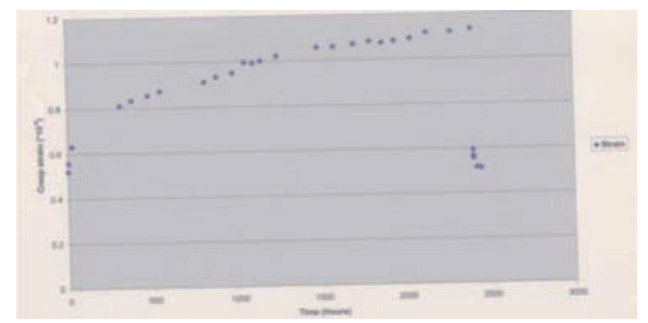

Figure 12. Creep of 14-day unsealed specimen.

\subsection{Discussion}

The whole experiment was lasted for $3 \frac{1}{2}$ months, and ASTM C 512:87 was followed. The shrinkage and creep curves of the specimens are shown as above; they are very similar with the general shrinkage and creep curves done by the others before. The load applied on the 7-day specimen was 4000 psi, and it was found that the loading at the end of the experiment is only 3850 psi and is about 3.75\% lesser. For the 14day specimen, the applied load is 4400 psi and was decreased to 4300 psi, which is about $2.27 \%$ lesser. Both of the specimens vary more than $2 \%$ from the correct value, which may cause little error on the data.

Figures 5-8 show the curves of 7-day shrinkage and creep properties. For the shrinkage, it was found that the specimen coated with an impervious material shrink much lesser than the unsealed specimen. The shrinkage of unsealed specimen up to 100 days is about $0.48 \times 10^{-3}$, but there is a little bit swelling for the sealed specimen. This is because the surface of the unsealed specimen was directly contacted with the surroundings, and thus, the hydration of cement gel can easily take place as the surrounding was an unsaturated condition. And for the sealed specimen, the impervious materials acted as a protective layer, which prevented the loss of water content to surrounding; this result of no shrinkage occurred on the specimen. For creep, both specimens have shown the same shape and with the same initial elastic strains which is about $0.6 \times 10^{-3}$. They have the same initial elastic strains as they are of the same mix and ages. The creep value of the sealed specimen is lesser than the unsealed specimen as they show different creep properties. The curve of sealed specimen shows the basic creep property, while the unsealed specimen shows the total creep. This is because the unsealed specimen was affected by humidity level of the surrounding. For creep recovery, both specimens recovered an instantaneous recovery once the applied stresses were removed. The instantaneous recovery of the unsealed specimen is about $0.57 \times 10^{-3}$, which is larger than the sealed specimen which is only $0.47 \times 10^{-3}$. This is because the moisture condition of the specimen is a factor affecting the modulus of elasticity, for instance, a wet specimen has a modulus higher by $0.45-0.60 \times 10^{-3}$ psi than the dry one. Both of them show the residual deformation, and it is about $0.5 \times 10^{-3}$ for unsealed specimen, which is a little bit greater than the sealed specimen. This is because some of the water had been flown out of the cement gel during the application of load, and this loss is unrecoverable.

Figures 9-12 shows the curves of 14-day shrinkage and creep properties. As the same as the 7-day specimen, the shrinkage of the unsealed specimen has shown much more shrinkage than that of sealed specimen, and the shrinkage up to 100 days is about $0.35 \times 10^{-3}$. Just like the 7-day specimen, there is no significant shrinkage but little swelling was occurred on the sealed specimen. This may be due to the water trapped by the impervious material and errors on the measurement of the strain value. For creep, both curves have shown the same initial elastic strain which is about $0.58 \times 10^{-3}$, and the rate of creep decrease with time. It was found that the total creep up to 100 days is about $0.55 \times 10^{-3}$ and the basic creep is about $0.27 \times 10^{-3}$. For the creep recovery, as the 7 -day specimen, they begin with the instantaneous recovery and followed by the creep recovery with a residual deformation. The instantaneous recovery of unsealed specimen is $0.63 \times 10^{-3}$ and is greater than the sealed specimen which is only $0.49 \times 10^{-3}$. This is because the water content of unsealed specimen is lower and thus the lower modulus of elastic.

Figures 6 and 10 have shown the curve of the shrinkage of unsealed specimen measured from the age of 7 and 14 days, respectively. The shape of the two curves is similar with a rapid increase in the beginning, and the rate of shrinkage decrease with time. The shrinkage value up to 100 days of the 7 -day specimen is $0.3 \times 10^{-3}$ more than that of 14 -day specimen. It is the fact that the two specimens are of the same mix, and their shrinkage value must be approximately equal. The difference in the shrinkage between them is the result of delay ( 7 days) in measurement. This is because the shrinkage of two specimens mainly consists of drying shrinkage and carbonation shrinkage; there existed carbon dioxide and unsaturated of surrounding environment that can directly contact specimen; that such kinds of shrinkage took place for the whole experiment; therefore, the 
rate of shrinkage that decreases with time is due to the decrease of cement gel in the specimen.

Figures 8 and 10 show the curve of the unsealed creep of the 7- and 14-day specimen. Despite the recovery part, two curves are of the same shape and approximately equal value. The strains at application of load of the two specimens with different age are nearly the same, and the total creep of the 14-day unsealed specimen is a little bit greater than that of the 7-day specimen. According to theories, we come to know that elastically modulus increase with time, so we can acquire that elastic strain decreases with time, creep also decreases with increase age of application of load. The experimental result does not show the same things; this is because stress/strength radio which was used in the experiment is not the same. The stress applied on the specimen is about $30 \%$ of the compression strength at the age of loading. This means that the loading applied on the 14-day specimen is lager than that of 7-day specimen with proportional to strength developed. Because of this, the strains on application of load of the two specimens are nearly the same. For the recovery part, both curves show the same shape. The instantaneous recovery value of the 14-day specimen is $0.6 \times 10^{-3}$ greater than 7-day specimen. This is because the creep of the 14-day specimen is higher, and the water loss from cement gel cause by application of stress is greater. The water content of the 14-day specimen is lower and thus with a higher elastic strain.

Figures 5 and 9 showed the curve of 7- and 14-day sealed specimens' shrinkage. The shape of the two curves are very similar, and the value tends to be a little bit negative which is about $-0.024 \times 10^{-3}$. The little bit swelling may due to water trapped on the surface just beneath the impervious materials or change of temperature and humidity of the surrounding. From Figures 1 and 2, we found that temperature and relative humidity of the room varied from time to time, and the increase in relative humidity and temperature may result in the decrease of magnitude of shrinkage.

Figures 8 and 12 show similar curve of the two unsealed specimen, but the basic creep of 7-day specimen is $0.08 \times 10^{-3}$ greater than that of 14 -day specimen, the basic creep mainly related to the strength, internal voids, and flow of cement paste of concrete. Although stress/strength ratio was used in this experiment, the giving in of internal voids is much more serious when load is applied on early-age concrete. Because of this, the 7-day basic creep is larger than the 14-day one. For recovery part, the instantaneous creep of both days' specimens is similar. This is because they are of similar water content and thus elastic strain. The residual deformation of 7-day specimen is higher than that of 14-day because its creep value is higher. As the giving in of internal void is unrecoverable, the creep does not recover too.

\section{CONCLUSION}

According to experimental results, it was found that the concrete undergoes instantaneous strain, which is equal to the elastic strain on that age once the loading was applied. The strain rate decreases with time, and such increase in strain is called creep. Once the load was removed, the concrete undergoes instantaneous recovery. Then, the creep recovery rate decreases with time and flattens out soon. From this, we know that creep is a time-dependent, but not completely reversible, phenomenon. Furthermore, it was found that the age of application of load has no effect on creep if stress/strength ratio was applied. But if same stress was applied, the creep is much greater for concrete loaded at early age than for older concretes. Such difference is mainly due to the strength development of the age of loading.

From this, we know that concrete should be cured for enough time before it was used to take loading. In nowadays construction industry, the speed of construction is very important. But the consideration of creep properties of the concrete structure is always ignored, and thus, many structures cannot serve for their design lifetime because of this kind of deformation. More attention should be paid for this matter during the design stage such as by some prediction formula or safety factor.

\section{REFERENCES}

American Concrete Institute. (1982). Prediction of creep, shrinkage, and temperature effects in concrete structures. Detroit, MI: ACl.

ASTM C 512:817. (2002). Standard test method for creep of concrete in compression. Philadelphia, PA: American Society for Testing and Materials.

BS 812: Part 2. (1995).

Daye, M. A., \& Fu, C. C. (1992). Creep and shrinkage of concrete: Effect of materials and environment. Detroit, MI: ACl.

Gilbert, R. I. (1988). Time effects in concrete structures. Developments in civil engineering. New York, NY: Elservier, p. 23.

Gvozdev, A. A. (1966). Creep of concrete. In: Mekhanika Tverdogo Tela, Moscow, pp. 137-52.

Hummel, A. (1959). Vom Einfluss der Zementart des Wasserzement-verhaltnissed und des Belastungsalters auf das Krienchen von Boton. Zement-Kala-Gips, 12(5), 181-187.

Kordina, K. (1960). Experiments on the influence of the mineralogical character of aggregates on the creep of concrete. RILEM Bulletin, 6, 7-22. 
L'Hermite, R. (1959). What do we know about plastic deformation and creep of concrete? RILEM Bulletin, 1, 37-41.

Meyers, B. L., \& Slate, F. O. (1970). Creep and creep recovery of plain concrete as influenced by moisture conditions and associated variables. Magazine of Concrete Research, 22(70), 21-25.

Nasser, K. W., \& Neville, A. M. (1967). Creep of old concrete at normal and elevated temperatures. ACl Journal, 64, 97-103.

Neville, A. M., \& Brook, W. H. (1983). Creep of plain and structural concrete. London, England: Construction Press.

Neville, A. M., \& Brooks, J. J. (1987). Concrete techonlogy. England: Longman.

Neville, A. M., Staunton, M. M., \& Bonn, G. M. (1966). A study of the relation between creep and the gain of strength of concrete. In: Symposium on Structure of Portland Cement Paste and Concrete, Special Report No, 90, Highway Research Board, Washington, DC, 1966, pp. 186-203.

Raina, V. K. (1989). Concrete for construction: Fact and practice. New Delhi, India: Shroff Publishers and Distributors Pvt. Ltd.
Troxell, G. E., Raphael, J. M., \& Davis, R. E. (1958). Long-time creep and shrinkage tests of plain and reinforced concrete. Proceedings of the American Society for Testing and Materials, 58, 1101-1120.

Waldron, C. J., Cousins, T. E., Nassar, A. J., Gomez, J. P., Nassar, A. J., \& Gomez, J. P. (2005).

Demonstration of use of high-performance lightweight concrete in bridge superstructure in Virginia. Journal of Performance of Constructed Facilities, 19(2), 146-155.

Wanger, O. (1958). Das Kriechen unbewehrten Betons. Berlin, Germany: Deutcher Ausschuss fur Stahlbeton, p. 74.

Wilby, C. B. (1991). Concrete materials and structures. Cambridge, England: Cambridge University Press.

Wilson, H., \& Malhotra, V. (1988). Development of high strength lightweight concrete for structural applications. International Journal of Cement Composites and Lightweight Concrete, 10(2), 79-90.

Yue, L. L. (1992). Creep recovery of plain concrete under uniaxial compaction. 